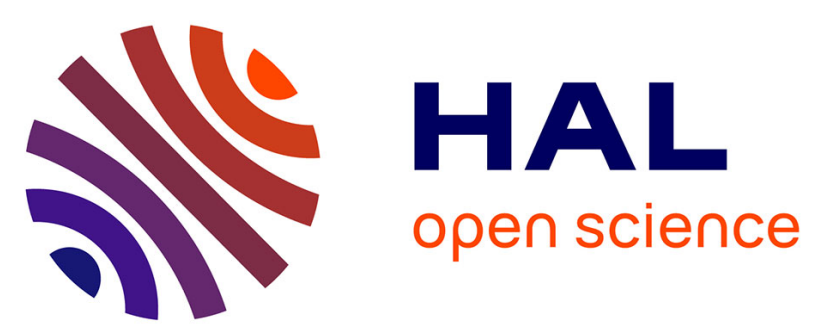

\title{
A Feedback Linearizing Controller for Relative Guidance Between Commercial Aircraft
}

Thierry Miquel, Felix Mora-Camino, Karim Achaibou

\section{To cite this version:}

Thierry Miquel, Felix Mora-Camino, Karim Achaibou. A Feedback Linearizing Controller for Relative Guidance Between Commercial Aircraft. AIAA GNC 2003, AIAA Guidance, Navigation and Control Conference, Aug 2003, Austin, United States. pp xxxx, 10.2514/6.2003-5410 . hal-00998755

\section{HAL Id: hal-00998755 \\ https://hal-enac.archives-ouvertes.fr/hal-00998755}

Submitted on 2 Jun 2014

HAL is a multi-disciplinary open access archive for the deposit and dissemination of scientific research documents, whether they are published or not. The documents may come from teaching and research institutions in France or abroad, or from public or private research centers.
L'archive ouverte pluridisciplinaire HAL, est destinée au dépôt et à la diffusion de documents scientifiques de niveau recherche, publiés ou non, émanant des établissements d'enseignement et de recherche français ou étrangers, des laboratoires publics ou privés. 


\title{
A FEEDBACK LINEARIZING CONTROLLER FOR RELATIVE GUIDANCE BETWEEN COMMERCIAL AIRCRAFT
}

\author{
Thierry MIQUEL ${ }^{*}$, Félix MORA-CAMINO ${ }^{\dagger}$, Karim ACHAIBOU $^{\star}$ \\ " LAAS du CNRS AND CENTRE D'ETUDES DE LA NAVIGAT ION AERIENNE, TOULOUSE, FRANCE \\ † LAAS du CNRS AND ECOLE NATIONALE DE L'A VIATION CIVILE, TOUlOUSE, FranCE \\ ${ }^{*}$ LAAS du CNRS, TOUlOUSE, FRANCE \\ EMAIL : miquel@cena.fr,Felix.MORA@enac.fr,achaibou@laas.fr
}

\begin{abstract}
During the last few years, several concepts concerning the delegation to commercial aircraft flight crew of some tasks currently performed by the air traffic controllers have emerged [3]. Among these new ideas, relative guidance has appeared to be of some interest to contribute to the enhancement of air traffic capacity [1] though it rises hard technical challenges. Indeed, this kind of maneuver appears difficult to perform manually, and may induce an excessive increase of the flight crew workload, thus requiring a new on-board automated function, as suggested in [7]. This paper investigates the design of an autopilot mode dedicated to the trailing aircraft for merging and maintaining station keeping behind a leading aircraft. The investigated approach is based on feedback linearization control. We use a new form of relative position error which results in a singularity free stabilizing controller. Moreover, we take explicitly into account the separation between the two aircraft in order to safely manage the maneuver. Some properties of such a controller are also discussed on the basis of a case study including wind.
\end{abstract}

\section{INTRODUCTION}

The anticipated traffic increase in air traffic encourages the design of new strategies to increase air traffic control capacity significantly while at the same time enhancing safety and flight efficiency.

So as to meet this challenge, new concepts such as the delegation to the flight crew of some tasks presently performed by air traffic controllers have emerged during the last few years [1].

A subset of this delegation concept is related to relative guidance of aircraft. This concept is supported by the European air traffic control agency. Indeed the objective of the 'Enhanced Sequencing and merging operations', which is one of the applications described in [3], is to redistribute tasks related to sequencing and merging traffic between the controllers and the flight crews. In enroute airspace and terminal area in a radar environment, the controller will be provided with a new set of instructions directing, for example, the flight crews to establish and to maintain a given time or distance from a designated aircraft.

The main challenge for the aircraft relative guidance concept is to enhance air traffic capacity by decreasing air traffic controller workload while at the same time preventing flight crew workload increase. To achieve these goals, new automated functions onboard aircraft must be developed; indeed, nowadays no automatic control mode is available on-board civil aircraft to perform this task.

Recent studies have investigated related problems for Unmanned Air Vehicles (UAV) and military aircraft. In [4] and [10], the control system was designed on a linearized model, whereas in [8] the proposed feedback linearizing control law exhibits a singular point when the desired relative position is zero which may result in infinitely large inputs. On the other hand, research for civil aircraft in this area is in its initial stage: in [1] station keeping is performed manually by the flight deck, whereas in [6] and [11] the authors consider a proportional, integral, and derivative (PID) control to control longitudinal station keeping. But very few papers concentrates on the automatic control of the merging maneuver before maintaining the desired position behind the leading aircraft. Indeed, the merging maneuver exhibits large nonlinearities which can not be handled by linearization. In [9], two approaches based on nonlinear control are presented: the first one is based on feedback linearizing control, whereas the second one is based 
on optimal control, but for both of them the separation between the two aircraft has not been taken explicitly into account during the design process. This may result in a loss of separation between the two aircraft during the merging maneuver.

In this context, this paper focuses on the design of a nonlinear controller which enable an aircraft to perform merging maneuvers and to maintain station keeping behind a designated aircraft. The investigated approach is based on feedback linearizing control. Such a control is applied to a new expression of relative position error. The interest of this new approach is that it results in a singularity free stabilizing controller. Moreover, it takes explicitly into account the separation between the two aircraft to safely manage the maneuver.

The relative guidance controller is confined in the horizontal plane. It provides reference values to the airspeed hold and heading hold autopilots. As others decoupled autopilot functions are available for the motion in the vertical plane, the flight crew remains free to manoeuvre in the vertical plane in case of unexpected situations.

The paper is organized as follows: in the preliminary section, reference frame and aircraft model are introduced. This leads to the nonlinear state space representation which is used in this paper. The subsequent section presents the design of the feedback linearizing controller. Then, some properties of such a controller are also discussed on the basis of a case study including wind. Finally, conclusions are raised.

\section{Preliminaries}

\section{REFERENCE FRAME}

In the following, the along track distance, denoted $\mathrm{TK}$, is aligned with the trailing aircraft ground speed vector, whereas the cross track distance, denoted XTK, is the right handed positive distance from the trailing to the leading aircraft. The heading angle of the trailing aircraft is denoted by $\psi$, its airspeed by V. Subscript L is added for all variables related to the leading aircraft. Since wind is considered is this paper, the track angle of the trailing aircraft is denoted by $\chi$.

Assuming that the earth is flat and non-rotating, it may be considered as an inertial frame. The track angle $\chi$ is the direction followed by the aircraft with respect to this inertial frame, whereas the heading angle $\psi$ is the direction followed by the aircraft with respect to the air. When there is no wind (i.e. $\mathrm{W}_{\mathrm{x}}=\mathrm{W}_{\mathrm{y}}=0$ ), those angles are equal.

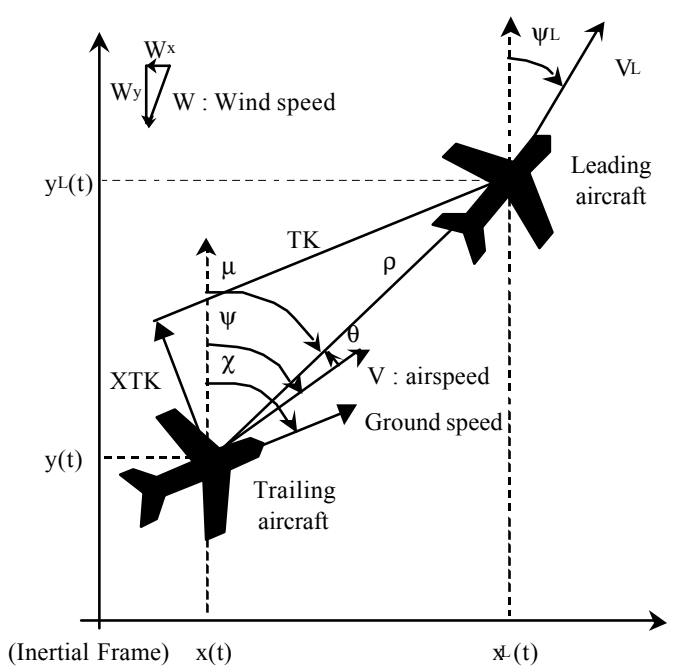

Figure 1 Reference frame

From Figure 1, the inertial position dynamics of the trailing aircraft are given by:

$$
\left\{\begin{array}{l}
\dot{x}=V \cdot \sin (\psi)+W_{x} \\
\dot{y}=V \cdot \cos (\psi)+W_{y}
\end{array}\right.
$$

Where $\left\{\mathrm{W}_{\mathrm{x}}, \mathrm{W}_{\mathrm{y}}\right\}$ are the wind components expressed in the inertial frame, and $\gamma$ the flight path angle of the aircraft.

Denoting by $\psi_{\mathrm{w}}$ the wind direction and $\mathrm{W}$ its velocity, and taking into account that the wind direction is the direction from where the wind is blowing (so $\psi_{\mathrm{W}}$ is zero if the wind is blowing from the North), the following relation holds:

$$
\left\{\begin{array}{l}
W_{x}=W \cdot \sin \left(\psi_{w}-\pi\right) \\
W_{y}=W \cdot \cos \left(\psi_{w}-\pi\right)
\end{array}\right.
$$

\section{AIRCRAFT DYNAMICS}

The trailing aircraft is supposed to fly in a fully coordinated fashion, i.e. the side-slip angle is always zero (airspeed and fuselage have the same direction).

Furthermore it is assumed that the following two decoupled autopilot functions are available onboard the trailing aircraft. These decoupled functions assume coordination between throttle, aileron and rudder, as in many modern jets.

- The airspeed hold autopilot controls the conventional airspeed $\mathrm{V}$ without affecting the aircraft's altitude. Denoting by $\mathrm{V}_{\mathrm{c}}$ the controlled airspeed, the airspeed dynamics may be modeled as 
a first order system for the purpose of control design:

$$
\dot{V}=\frac{V_{c}-V}{\tau_{V}}
$$

- The heading hold autopilot controls the heading $\psi$ without affecting the aircraft's airspeed. Heading is assumed to be controlled by the bank angle $\varphi$. For small bank angle and loading factors, the following relation between heading rate and bank angle holds, where $\mathrm{g}$ is the acceleration of gravity, $\varphi$ the bank angle and $\mathrm{V}$ the actual airspeed:

$$
\psi=\frac{g \cdot \varphi}{V}
$$

Denoting by $\varphi_{\mathrm{c}}$ the controlled bank angle, the bank angle dynamics may be modeled as a first order for the purpose of control design:

$$
\dot{\varphi}=\frac{\varphi_{c}-\varphi}{\tau_{\varphi}}
$$

These first-order models for airspeed and bank angle dynamics are usually considered as good models for inner loops flight dynamics [10].

\section{RELATIVE POSITION KIN EMATICS}

In the following, $\rho$ denotes the (horizontal) range between the leading and the trailing aircraft, and $\mu$ the relative bearing between those aircrafts. From Figure 1, they are related to the inertial positions:

$$
\left\{\begin{array}{l}
x=x_{L}-\rho \cdot \sin (\mu) \\
y=y_{L}-\rho \cdot \cos (\mu)
\end{array}\right.
$$

Range and relative bearing are of direct interest for the achievement of safe relative guidance. In addition, they could be derived from the TCAS surveillance or from future Automatic Dependent Surveillance Broadcast (ADS-B) systems [2].

Taking into account ( 1) and assuming the same wind for the two aircraft, the time derivative of (6) leads to:

$$
\left\{\begin{array}{l}
\dot{\rho}=V_{L} \cos \left(\psi_{L}-\mu\right)-V \cos (\psi-\mu) \\
\rho \mu=V_{L} \sin \left(\psi_{L}-\mu\right)-V \sin (\psi-\mu)
\end{array}\right.
$$

Conversely, range and relative bearing can be derived from to the along track distance TK and the cross track distance XTK by (see Figure 1):

\footnotetext{
${ }^{1}$ Traffic Collision Avoidance System
}

$$
\left\{\begin{array}{l}
\rho=\sqrt{T K^{2}+X T K^{2}} \\
\mu=\chi+\operatorname{arctg}\left(\frac{X T K}{T K}\right)
\end{array}\right.
$$

The preceding relationships are useful to translate the objectives manipulated by air traffic controller and pilots (i.e. merge $5 \mathrm{NM}$ behind, $1 \mathrm{NM}$ left) into variables manipulated by the controller.

\section{STATE SPACE REPRESENTATION}

Gathering (3), (4) and (7) leads to the following state space representation of the relative guidance kinematics, where $\underline{u}$ denotes the control vector and $\underline{\mathrm{x}}$ the state vector:

$$
\begin{aligned}
& \underline{\dot{x}}=f(\underline{x})+g(\underline{x}) \underline{u} \\
& \left\{\begin{array}{l}
\underline{x}=\left[\begin{array}{llll}
\rho & \mu & V & \psi
\end{array}\right]^{T} \\
\underline{u}=\left[\begin{array}{ll}
V_{c} & \varphi
\end{array}\right]^{T}
\end{array}\right.
\end{aligned}
$$

This state space representation declares exogenous the heading $\psi_{\mathrm{L}}$ and the velocity $\mathrm{V}_{\mathrm{L}}$ of the leading aircraft. Indeed, those variables can be made available thanks to air/air data communications.

The dynamics (5) of the controlled bank angle $\varphi$ are not taken into account since they are much faster than the relative position dynamics; nevertheless, they are taken into account during simulation $\mathrm{s}$.

The proposed control scheme is presented hereafter:

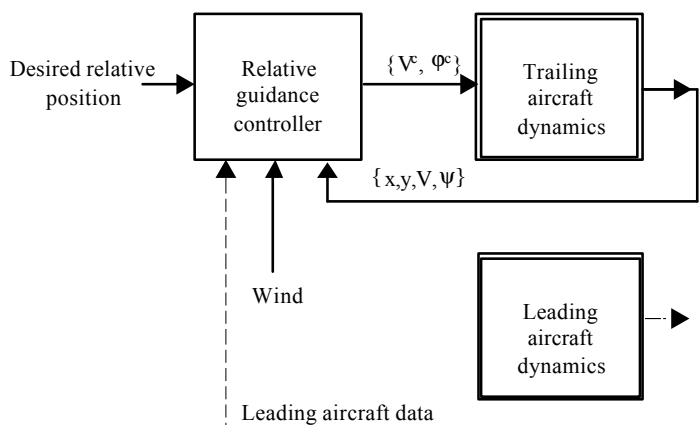

Figure 2 Block diagram of the relative guidance control system

The purpose of the next section is to design the relative guidance controller so that the controlled variables $V_{c}$ and $\varphi_{c}$ allows the trailing aircraft to reach the desired position relatively to the leading aircraft. 


\section{RELATIVE GUIDANCE CONTROLLER DESIGN}

\section{RELATIVE POSITION ERROR}

In this section, we derive a new form of the relative position error which takes explicitly into account the separation between the two aircraft in order to safely manage the maneuver. Moreover, it results in a singularity free stabilizing controller.

The relative position error, or output vector, is chosen as follows:

$$
\underline{y}=h(\underline{x})=\left[\begin{array}{c}
\rho \\
\int_{\mu_{0}}^{\mu} \rho \cdot d \mu
\end{array}\right]
$$

From a practical point of view, $\dot{\rho}$ is the convergence velocity and $\rho \mu$ the normal relative velocity.

The first derivative of (10 ) leads to (7), whereas the second derivative leads to:

$$
\underline{y}=\left[\begin{array}{c}
\ddot{\rho} \\
\rho \ddot{\mu}+\dot{\rho} \dot{\mu}
\end{array}\right]=\Delta_{0}(\underline{x})+\Delta(\underline{x}) \cdot \underline{u}
$$

$\Delta_{0}(\underline{x})=\left[\begin{array}{l}V \cos (\psi-\mu) / \tau_{V} \\ +\dot{\mu}\left(V_{L} \sin \left(\psi_{L}-\mu\right)-V \sin (\psi-\mu)\right) \\ ----------------- \\ V \sin (\psi-\mu) / \tau_{V} \\ -\mu\left(V_{L} \cos \left(\psi_{L}-\mu\right)-V \cos (\psi-\mu)\right)\end{array}\right]$

$\Delta(\underline{x})=\left[\begin{array}{cc}-\cos (\psi-\mu) / \tau_{V} & g \cdot \sin (\psi-\mu) \\ -\sin (\psi-\mu) / \tau_{V} & -g \cdot \cos (\psi-\mu)\end{array}\right]$

\section{FEEDBACK LINEARIZING CONTROL}

The feedback linearizing technique [5] consists in computing a control law that compensates the nonlinearities of the system to enforce linear dynamics to its outputs. A relative degree is determined from the affine representation for each output variable : this relative degree fixes the order which can be assigned to the output dynamics.

As the rank of the matrix $\Delta(\underline{x})$ defined in (13) is always 2 and presents no singularity in the state space, there is no inner dynamic. So, it results in a singularity free stabilizing controller and the output dynamics can be chosen without damage for the overall stability of the system. Inverting (13 ) leads to the following general non linear control law:

$$
\begin{gathered}
\underline{u}=\Delta(\underline{x})^{-1}\left(\underline{\ddot{y}}-\Delta_{0}(\underline{x})\right)=\Delta(\underline{x})^{-1} \underline{\ddot{y}}+l(\underline{x}) \\
\Delta(\underline{x})^{-1}=\left[\begin{array}{cc}
-\tau_{V} \cos (\psi-\mu) & -\tau_{V} \sin (\psi-\mu) \\
\sin (\psi-\mu) / g & -\cos (\psi-\mu) / g
\end{array}\right] \\
l(\underline{x})=\left[\begin{array}{l}
V+\tau_{V} \dot{\mu}\left[V_{L} \sin \left(\psi-\psi_{L}\right)-V \sin (2(\psi-\mu))\right] \\
-\mu \dot{\mu}\left[V_{L} \cos \left(\psi-\psi_{L}\right)+V \cos (2(\psi-\mu))\right] / g
\end{array}\right]
\end{gathered}
$$

For the derivation of the feedback linearizing controller, let us select the following dynamics of the output vector:

$\underline{\ddot{y}}=\left[\begin{array}{c}\ddot{\rho} \\ \rho \ddot{\mu}+\dot{\rho} \dot{\mu}\end{array}\right]=\left[\begin{array}{c}-2 \xi_{\rho} w_{\rho} \dot{\rho}-w_{\rho}^{2}\left(\rho-\rho_{d}\right) \\ -2 \xi_{\mu} w_{\mu} \rho \dot{\mu}-w_{\mu}^{2}\left(\mu-\mu_{d}\right)\end{array}\right]$

Where $\xi_{\rho}, w_{\rho}, \xi_{\mu}$ and $w_{\mu}$ are positive numbers, and $\rho_{\mathrm{d}}$ and $\mu_{\mathrm{d}}$ respectively the desired range and relative bearing derived from the desired along track and cross track distances thanks to (8).

From a practical point of view, the choice of a faster dynamics for the normal relative velocity compared to the convergence velocity (i.e. $\left.w_{\mu} \sqrt{1-\xi_{\mu}^{2}}>>w_{\rho} \sqrt{1-\xi_{\rho}^{2}}\right)$ allows to neglect $\dot{\rho}$ in the expression of $\rho \ddot{\mu}+\dot{\rho} \dot{\mu}$ : so, the second equation of (17) can be viewed as a way to settle the dynamics of the relative bearing $\mu$, whereas the first equation of (17) settles the dynamics of the range $\rho$.

The control law is then given by inserting (17 ) into (14). After that, the inputs (i.e. the controlled bank angle and airspeed) of the relative guidance controller are limited at the follow ing 'safe' values:

$$
\left\{\begin{array}{l}
-\varphi_{\max } \leq \varphi_{c} \leq+\varphi_{\max } \\
V_{\min } \leq V_{c} \leq V_{\max }
\end{array}\right.
$$

\section{CASe STUdy}

\section{SCENARIO}

In this section, a scenario is designed in order to evaluate the properties of the control laws previously designed.

The leading aircraft starts at $=0 \mathrm{NM}, \mathrm{y}_{0}=0 \mathrm{NM}$, with initial conventional airspeed and heading of $240 \mathrm{kts}$ and 90 degrees respectively. It is supposed to broadcast its data every second.

The controlled bank angle of the leading aircraft is always zero, except between $600 \mathrm{sec}$ and $630 \mathrm{sec}$ 
where the leader changes its heading by about 50 degrees through a 20 degrees controlled bank angle.

The controlled conventional airspeed of the leading aircraft is first set at $240 \mathrm{kts}$ for $\mathrm{t} \leq 300 \mathrm{sec}$, then is set to $190 \mathrm{kts}$.

The trailing aircraft starts at $\mathrm{x}_{0}=+8 \mathrm{NM}, \mathrm{y}_{0}=-8 \mathrm{NM}$, with initial conventional airspeed and heading of $240 \mathrm{kts}$ and 0 degrees respectively.

The simulation period lasts $15 \mathrm{~min}(900 \mathrm{sec})$, and the requested separation for the trailing aircraft remains constant and equal of $5 \mathrm{NM}$ behind the leading aircraft.

The whole maneuver is supposed to take place within a wind of 20 kts blowing from North; furthermore, both aircraft are assumed to fly at FL80.

During the maneuver, the inputs (i.e. the controlled bank angle and airspeed) of the relative guidance controller are limited at the following 'safe' values:

$$
\left\{\begin{array}{l}
-20 \mathrm{deg} . \leq \varphi_{c} \leq+20 \mathrm{deg} . \\
170 k t s \leq V_{c} \leq 250 k t s
\end{array}\right.
$$

The time constants $\tau_{\mathrm{V}}$ and $\tau_{\varphi}$ of the airspeed and heading hold autopilot are set to the following values:

$$
\left\{\begin{array}{l}
\tau_{V}=40 \mathrm{sec} \\
\tau_{\varphi}=5 \mathrm{sec}
\end{array}\right.
$$

The values of the constants defining the output vector dynamics have been chosen as follows:

$$
\left\{\begin{array}{l}
w_{\rho}=0.05 \mathrm{sec}^{-1} \\
\xi_{\rho}=1 \\
w_{\mu}=0.05 \mathrm{sec}^{-1} \\
\xi_{\mu}=0.6
\end{array}\right.
$$

\section{RESULTS}

The scenario has been constructed such as no control of the trailing aircraft trajectory will result in a minimum range between the two aircraft equals to zero.

The movement of the leading and trailing aircraft in the horizontal plane are shown in Figure 3. The curvature of the trajectory at the beginning of the encounter comes from the saturation of the controlled outputs. It clearly shows the tendency of the controller to ensure separation between the two aircr aft.

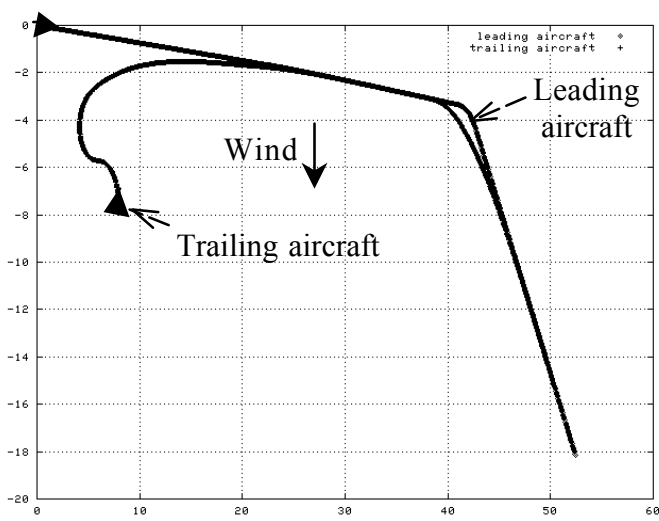

Figure 3 Movement of the trailing aircraft in the horizontal plane (axes in NM)

The evolution in the actual range between the leading and the trailing aircraft is shown in Figure 4. As intended, the slant range tends to the desired 5 NM. Furthermore, the controller tends to stick to that desired value despite the changes in leading aircraft heading and airspeed. This is an encouraging behaviour from the robustness point of view.

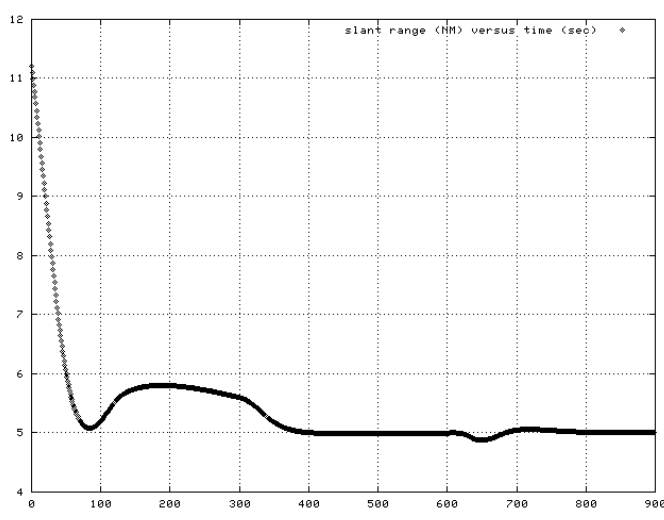

Figure 4 Actual range (in NM) between the leading and the trailing aircraft as a function of time (in sec)

Figure 5 and Figure 6 show respectively the evolution of controlled and actual conventional airspeed and bank angle: 


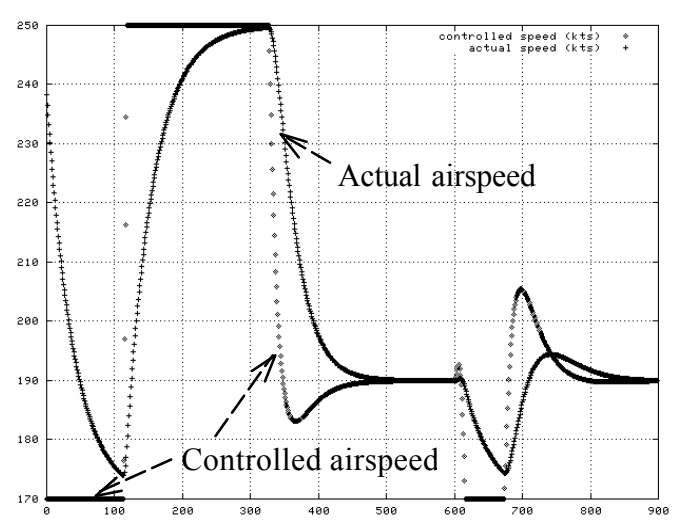

Figure $5 \quad$ Controlled and actual airspeed (in kts) as a function of time (in sec)

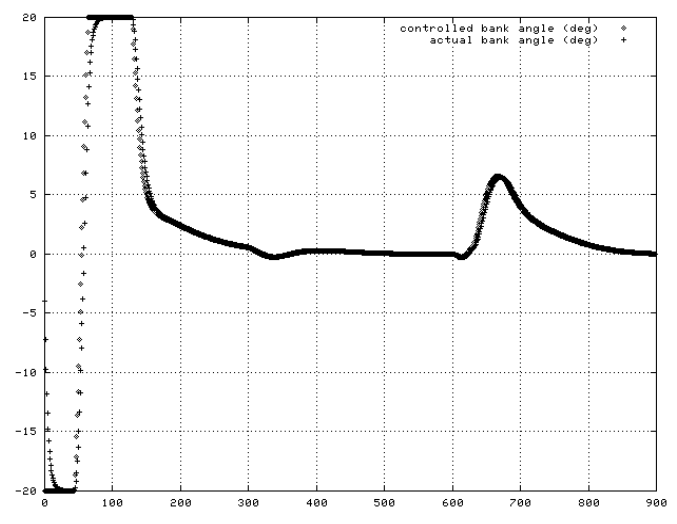

Figure 6 Controlled and actual bank angle (in degrees) as a function of time (in sec)

The last figure shows that neglecting the bank angle dynamics during the design of the controller does not have a significant impact: indeed, it just slightly delays the actual bank angle.

Finally, the load factor as a function of time in represented in the following figure: it shows that the maneuver remains quite comfortable for passengers:

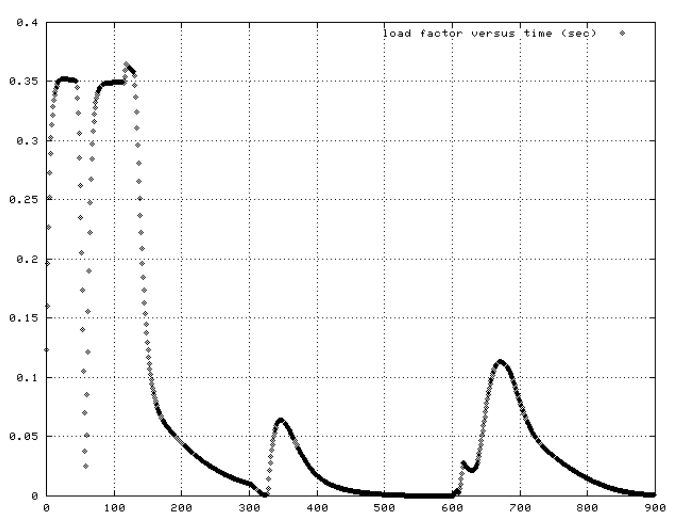

Figure 7 Load factor as a function of time (in $\mathrm{sec})$

Note : The load factor has been computed as follows:

$$
\begin{aligned}
& n=\frac{1}{g} \cdot|| \frac{d \vec{V}}{d t} \mid=\sqrt{n_{x}^{2}+n_{y}^{2}} \\
& \left\{\begin{array}{l}
n_{x}=\frac{\dot{V}}{g} \\
n_{y}=\frac{V \cdot \psi}{g}
\end{array}\right.
\end{aligned}
$$

\section{CONCLUSION}

In this paper, the design of a controller to perform relative guidance maneuver from a designated aircraft has been considered.

The proposed approach relies on feedback linearizing control. The proposed design is based on a new form of relative position error which results in a singularity free stabilizing controller. Moreover, we take explicitly into account the separation between the two aircraft in order to safely manage the maneuver.

The paper has focused on a separation objective expressed in terms of distance. Nevertheless, some simulations have shown the interest to express the separation objective in terms of delay [1]. So, provided that the delay criteria is translated into a separation objective, the proposed control design approach can be easily extended to this case.

This ap proach appears quite interesting. It deserves further studies, especially on the robustness of such a controller to noisy data from the leading aircraft and to gust of wind. In addition, a special attention will be given on neglected dynamics. 


\section{REFERENCES}

[1] Agelii M., Olausson C., Flight deck simulations of station keeping, ATM 2001 R\&D seminar, Santa Fe, paper no. 17

[2] Barhydt R., Warren A., Development of Intent Information Changes to Revised Minimum Aviation System Performance Standards for Automatic Dependent Surveillance Broadcast (RTCA/DO-242A), NASA/TM -2002, may 2002

[3] European commission \& Eurocontrol CARA/ASAS Activity 5 description of a first package of GS/AS applications, version 2.2, september 2002

[4] Giulietti F., Pollini L., Innocenti M., Autonomous Formation Flight, IEEE Control Systems Magazine, December 2000

[5] Isidori A., Nonlinear control systems, Springer-Verlag, 1989

[6] Ivanescu D., Hoffman E., Zeghal K., Impact of ADS-B link characteristics on the performances of in-trail following aircraft, AIAA Guidance, Navigation and Control Conference, Monterey, USA, August 2002

[7] Jenkinson L.R., Caves R. E., Rhodes D. P., Automatic formation flight: a preliminary investigation into the application to civil operations, Loughborough university of technology, England, 1995

[8] Li S.M., Boskovic J.D., Mehra R.K., Globally stable automatic formation flight control in two dimensions, AIAA Guidance, Navigation and Control Conference. Montreal, August 2001, Paper No. 20014046

[9] Miquel T., Mora-Camino F., Relative guidance of aircraft: analysis and comparison of two control approaches, World Aviation Congress, November 2002, Paper No. 02WAC-55

[10] Pachter M., D’Azzo J.J., Dargan J.L., Automatic formation flight control, Journal of guidance, control and dynamics, vol. 17, pp 1380-1383, 1994

[1 1] Vanken P., Hoffman E., Zeghal K., Influence of speed and altitude profile on the dynamics of in-trail following aircraft, AIAA-20004362 